\title{
O ESTUdo DE FUNÇÕES ATRAVÉs DE PROBLEMAS MATEMÁTICOS: APLICAÇÃO EM UMA TURMA DO PROEJA - PONTES E LACERDA - MT
}

\author{
THE STUDY OF FUNCTIONS OF 1ST GRADE THROUGH MATHEMATICAL \\ PROBLEMS: APPLICATION IN A CLASSROOM OF PROEJA - PONTES E \\ LACERDA - MT
}

DOI: http://dx.doi.org/10.23926/RPD.2526-2149.2019.v4.n1.p96-113.id380

\section{Fabio Antunes Brun de Campos}

Mestrando do Programa de Pós-graduação em Ensino de Ciências e Matemática (PPGECEM-UNEMAT) Professor de Matemática da Universidade Estadual de Mato Grosso (UNEMAT) fabio.antunes.campos@gmai 1.com

\section{Fabíola de Souza Leal Antunes \\ Licencianda em Matemática pela Universidade Estadual de Mato Grosso (UNEMAT) fabiolasouzaleal@gmail.com}

\section{Cláudia Landin \\ Negreiros}

Doutora em Educação Pela

Universidade Federal do Rio

Grande do Sul (UFRGS)

Professora do Programa de

Pós-graduação em Ensino de

Ciências e Matemática

(PPGECEM-UNEMAT)

clnegreiros@unemat.br
Resumo: Este trabalho apresenta uma prática de ensino realizada com os alunos da turma do $4^{\circ}$ semestre do Programa Nacional de Integração da Educação Profissional - PROEJA, do Curso Técnico em Comércio. $\mathrm{Na}$ prática foram realizadas construções de funções do $1^{\circ}$ grau e foi apresentado para os alunos, 4 questões matemáticas sobre esse conteúdo que se relacionassem com as experiências de vida deles. Para isso, a pesquisa utilizou-se da abordagem qualitativa e buscou discutir importância da Resolução de Problemas e da Etnomatemática, por meio de atividades com tecnologias digitais nessa turma do PROEJA. Os alunos mostraram interesse nas práticas envolvendo as tecnologias digitais e nas questões apresentadas em sala de aula, conseguindo perceber que o conteúdo de função possui aplicação em suas realidades. Como resultado dessa prática, destaca-se a importância do docente em reconhecer e aproveitar os saberes dos estudantes dessa modalidade de ensino nas atividades de sala de aula, assim como o ensino da Matemática por meio da resolução de problemas contextualizados e criados com o auxílio do software GeoGebra.

Palavras-chave: Educação de Jovens e Adultos - EJA; PROEJA; Etnomatemática; Resoluções de Problemas; GeoGebra; Tecnologias Digitais

\begin{abstract}
This work presents a teaching practice carried out with the students of the 4th semester of the National Program of Integration of Professional Education - PROEJA, of the Technical Course in Commerce. In practice, constructions of 1 st grade functions were carried out and 4 mathematical questions about this content were presented to the students that relate to their life experiences. For this, the research used the qualitative approach and sought to discuss the importance of Problem Solving and Ethnomathematics, through activities with digital technologies in this class of PROEJA. The students showed interest in the practices involving the digital technologies and in the questions presented in the classroom, being able to perceive that the content of function has application in their realities. As a result of this practice, the importance of the teacher in recognizing and taking advantage of the students' knowledge of this modality of teaching in the activities of the classroom, as well as the teaching of Mathematics through the resolution of problems contextualized and created with the aid of the software GeoGebra.
\end{abstract}

Keywords: Youth and Adult Education - EJA; Ethnomathematics; Resolutions of Problems; GeoGebra; Digital Technologies. 


\section{INTRODUÇÃO}

Este trabalho surge de um projeto de extensão realizado no Instituto Federal de Educação Ciência e Tecnologia de Mato Grosso - IFMT - Campus Pontes e Lacerda, denominado: “GeoGebra: Capacitação para Professores de Matemática”, em 2017. Curso este que envolveu tanto professores atuantes na educação básica pública, quanto acadêmicos do curso de Licenciatura em Matemática e em Física dessa instituição.

O GeoGebra, segundo Borba, Silva e Gadanidis (2016), foi criado por Markus Hohenwarter e consolidado por pesquisadores, professores e estudantes como uma tecnologia inovadora na educação matemática. O software permite elaborar gráficos, montar figuras planas, espaciais, escrever equações, resolver cálculos, e é possível movimentar, mudar a cor das figuras e formas, criar novas formas etc. Em outras palavras, o software apresenta vários dinamismos que potencializam a prática pedagógica.

Nesse sentido, os softwares educativos, segundo Lopes Júnior (2013), podem aprimorar a didática em sala de aula, especificamente os processos de ensino e de aprendizagem, além de possibilitar a experimentação matemática, ou seja, "acarreta novas possibilidades de conceituação, dentro de uma visão construtivista, onde o aluno não é mais ensinado, mas é o artífice do seu próprio conhecimento" (LOPES JÚNIOR, 2013, p. 10).

No que concerne ao aluno da Educação de Jovens e Adultos, é aquele que não teve "acesso ou continuidade de estudos no ensino fundamental e médio na idade própria" (BRASIL, 2007 , art. $37^{\circ}$ ). E com o intuito de ampliar as possibilidades de acesso desse aluno é que surge o Programa Nacional de Integração da Educação Profissional - PROEJA, que se configura como

[...] uma política pública que tem por objetivo a elevação da escolaridade com profissionalização, no sentido de contribuir para a integração sociolaboral de grande contingente de cidadãos cerceados do direito de concluir a educação básica e de ter acesso a uma formação profissional de qualidade. (COSTA FILHO; COSTA, 2017, p. 84).

Nessa direção, o PROEJA busca oportunizar aos jovens e adultos que por algum motivo não cursaram o Ensino Médio na idade certa, mas ao retornarem para as salas de aula cursem, concomitantemente, o Ensino Médio e um curso técnico. Tal oportunidade visa contribuir para a elevação da escolaridade desses sujeitos, ampliando a sua inserção no mercado de trabalho com mão de obra especializada.

Por outro lado, o ensino para os alunos desse programa constitui-se em um trabalho desafiador para muitos docentes. Desafios esses que se configuram na falta de formação inicial e/ou continuada para se trabalhar com esse público, e em como superar as dificuldades 
conceituais apresentadas por estes. Tais fatores podem ser decorrentes da ausência desses em sala de aula por determinado período, ou ainda, dos desafios que os mesmos encontram ao retornarem ao meio escolar, visto que o estudo, muitas vezes, não é tido como prioridade, frente às necessidades do sustento de sua família ou do seu próprio sustento (COSTA FILHO; COSTA, 2017); (MOREIRA, 2012).

Em relação às metodologias de ensino nessa modalidade, Shiroma e Lima Filho (2011) comentam que, por se tratar de um alunado diferenciado (PROEJA), faz-se necessário, por parte dos professores que nela atuam, um empenho redobrado "para construírem metodologias, recursos didáticos apropriados e formas inovadoras de ensinar e avaliar para que não reforcem, também no espaço da EJA, as experiências vividas pelos alunos de múltiplas exclusões" (SHIROMA; LIMA FILHO, 2011, p. 733). Em vista disso, é que "o professor necessita revisar muitos conteúdos, preparar aulas e materiais apropriados a esta modalidade" (SHIROMA; LIMA FILHO, 2011, p. 733).

Comentando um pouco mais sobre os docentes inseridos nessa modalidade de educação, a pesquisa realizada por Costa Filho e Costa (2017) apresenta um gestor escolar discorrendo sobre a necessidade da formação inicial e/ou continuada para prepará-los, ou seja:

Desde o princípio e, talvez, por essa deficiência na formação - "verificou-se o preconceito por parte do corpo docente quanto ao nível dos estudantes matriculados na nova modalidade, pois nunca souberam extrair daqueles estudantes as suas experiências, vivencias dos mesmos nos cursos escolhidos" (COSTA FILHO; COSTA, 2017, p. 89).

Tal formação, inicial ou continuada de professores na EJA, torna-se necessária pelo elevado índice de evasão escolar no PROEJA. Esse é, então, um dos aspectos discutidos por Moreira (2012). Para a autora,

A elevada evasão escolar no PROEJA demonstra a necessidade de se estudar os fatores que contribuem para esse fenômeno, como aqueles referentes à escola, à família ou mesmo ao próprio indivíduo. A evasão escolar é um processo que tem seu início e o seu processo, muitas vezes possíveis de serem identificados, monitorados e, quando possível, evitados (MOREIRA, 2012, p. 13).

Comentando sobre a EJA, Shiroma e Lima Filho (2011) discutem o quão preocupante é esse aspecto, em se tratando do alunado. Segundo os autores:

O índice de desistência e evasão é motivo de preocupação e requer providências tanto das instituições ofertantes, quanto das políticas públicas. Premidos pelas necessidades, alguns alunos deixam o curso quando arrumam emprego, por dificuldades financeiras, e outros o abandonam mesmo pelo cansaço de enfrentar diariamente a terceira jornada. Para fazer frente a esta situação, docentes constroem alternativas para acompanhamento e apoio aos trabalhadores que buscam o estudo. (SHIROMA; LIMA FILHO, 2011, p. 734) 
Pensando nesses fatores, e assim como Moll (2004, p. 17), que acredita que fazer-se docente de jovens e adultos "implica disposição para aproximações que permanentemente transitam entre saberes constituídos legitimados no campo das ciências, das culturas e das artes e saberes vivenciais que podem ser legitimados no reencontro com o espaço escolar", é que surge este trabalho, que teve como objetivo discutir a importância da Resolução de Problemas e da Etnomatemática, por meio de atividades com tecnologias digitais na turma do $4^{\circ}$ semestre PROEJA.

Assim utilizamos da abordagem qualitativa e da triangulação para a produção e análise dos dados, esta pesquisa teve como instrumentos de análise: questionários, entrevistas, imagens e caderno de nota do professor regente da disciplina de Matemática, na sala de aula em questão.

Ainda sobre a pesquisa qualitativa, Tuzzo e Braga (2016, p. 145) afirmam que a mesma é realizada de forma "analítica, explicativa, ou seja, ela é regida pelos dados que gerarão conclusões e reflexões, baseados na complexidade da sociedade onde a pesquisa foi gerada". E sobre a triangulação, Marcondes e Brisola (2014, p. 203) explicam que a mesma permite ao pesquisador "lançar mão de três técnicas ou mais com vistas a ampliar o universo informacional em torno de seu objeto de pesquisa”.

Então, para discutir a importância da Resolução de Problemas e da Etnomatemática, por meio de atividades com tecnologias digitais, realizamos uma prática elaboração de gráficos de Função do $1^{\circ}$ Grau com a turma do $4^{\circ}$ semestre PROEJA e uma segunda, onde apresentamos problemas matemáticos criados com o auxílio do software GeoGebra. Intencionando, assim, valorizar as experiências de vida desses alunos, seu meio social e suas histórias de vida, no processo de ensino da Matemática.

Esperamos então, que da mesma forma que este trabalho contribuiu com a visão docente de nós, participantes do "GeoGebra: Curso de Capacitação para Professores de Matemática", que este trabalho, venha contribuir para outras discussões e visão docente, sobre o ensino da matemática envolvendo as Tecnologias Digitais, a Resolução de Problemas e a Etnomatemática na educação de jovens e adultos.

\section{VALORIZANDO EXPERIÊNCIAS NO ENSINO DA MATEMÁTICA PARA JOVENS E ADULTOS}

O ser humano, ao longo da vida, vai adquirindo saberes: populares, culturais e científicos, mesmo antes de adentrar em uma escola (D’AMBRÓSIO, 2008). Pensando nisso, mais especificamente nos jovens e adultos, principalmente naqueles que, por algum motivo, foram levados a abandonar seus estudos, tais saberes encontram-se desenvolvidos por meio das 
experiências ocorridas no trabalho, com as histórias vivenciadas em seu meio social e com os diversos processos de ensino realizados durante o período em que permaneceram fora dos ambientes escolares.

Nesse sentido, D’Ambrósio (2008) destaca que no ensino para os jovens e adultos, o "ponto crucial é reconhecer que esses estudantes não chegam à escola com "a cabeça vazia", ou, como dizem alguns filósofos da educação, a mente humana não é uma tábula rasa”, mas sim, que essas vivências e histórias devam ser consideradas, pois para o autor,

Uma grande dificuldade do processo educacional é que o professor não conhece o ambiente cultural dos estudantes e, portanto, fica difícil reconhecer o que o estudante já sabe e o que é capaz de fazer. Portanto, o professor toma como referência seu próprio ambiente cultural, sua cultura, suas experiências prévias. Esse é um dos maiores equívocos da educação. (D’AMBRÓSIO, 2008, p. 10)

Assim é que os docentes e as instituições de ensino devem incentivar e promover situações nas quais esses alunos se envolvam de maneira ativa, permitindo, por exemplo, que os mesmos tragam para as salas de aula suas histórias, suas vivências. O professor, então, nesse processo, precisa ser o mediador da construção de conhecimentos nesses ambientes, conduzindo-os a descobrir, a enxergar, desenvolver e aplicar os conhecimentos disciplinares em seu contexto de vida.

Essa postura do professor, especificamente o de Matemática, vista sob essa perspectiva, é a mesma praticada em grupos culturais, tais como: as sociedades indígenas, grupos de trabalhadores, classes profissionais, grupos de crianças pertencentes a uma determinada faixa etária, etc. (ROSA; OREY, 2006).

Seguindo, então, essa orientação, os conceitos e conteúdos matemáticos trabalhados em sala, emergem das situações imediatas dos estudantes com o seu meio, e os conteúdos matemáticos, então, são trabalhados por meio das interações sociais, culturais e naturais, que gradativamente vão sendo inseridas no processo de ensino.

Essa metodologia que visa valorizar as interações dos estudantes nos ambientes educacionais é denominada por D’Ambrósio de Etnomatemática, que segundo Rosa e Orey (2006):

[...] é o modo pelo qual culturas específicas (etno) desenvolveram, ao longo da história, as técnicas e as idéias (tica) para aprender a trabalhar com medidas, cálculos, inferências, comparações, classificações e modos diferentes de modelar o ambiente social e natural no qual estão inseridas, para explicar e compreender os fenômenos que neles ocorrem (matema). (ROSA; OREY, 2006, p.7).

O termo Etnomatemática, de acordo com D’Ambrósio (2008, p. 8), "significa o conjunto de artes, técnicas de explicar e de entender, de lidar com o ambiente social, cultural e natural, 
desenvolvido por distintos grupos culturais". Ainda segundo esse autor, ao se "praticar etnomatemática, o educador estará atingindo os grandes objetivos da Educação Matemática, com distintos olhares para distintos ambientes culturais e sistemas de produção" (D’AMBRÓSIO, 2008, p. 10).

Para Orey e Rosa (2012), um “aspecto primordial desse processo é auxiliar os alunos a perceberem o próprio potencial matemático através do reconhecimento da importância da cultura para a valorização da própria identidade". Nesse sentido, contextualizar as diversas situações de problemas matemáticos que se apresentam ou ocorrem no cotidiano dos jovens e adultos colabora com as inúmeras possibilidades de soluções de problemas para a vida real desses educandos (PEREIRA, 2017). E dessa forma, o problema deixa de ser visto como um recurso voltado apenas para a resolução de uma atividade matemática apresentada em sala de aula (GONÇALVES; BANDEIRA, 2013), e passa a ser visto como um elemento propulsor do processo de construção de conhecimentos que se estabelece fora da escola.

Especificamente no ensino pautado por meio da Resolução de Problemas, e de acordo com Ferreira, Pereira e Lemos (2018, p. 109), tem-se que: “os problemas são valorizados não apenas como um propósito para aprender Matemática, mas também como principal meio de fazer matemática". Nessa perspectiva de ensino, essa ciência surge em meio a um problema ou uma situação-problema e os conceitos matemáticos emergem dos contextos apresentados nesse problema, mostrando, então, dessa forma, que a Matemática estudada na escola se aplica na vida dos sujeitos.

De acordo com Ferreira e Buriasco (2015, p. 454), um dos principais papéis do contexto escolar é potencializar as características específicas da Matemática, quais sejam: realizar cálculos, criar um modelo matemático, representar uma situação matematicamente por gráficos ou tabelas, entre outras. Tais características devem ser contempladas no processo de ensino, a que os autores denominam: "matematizar".

Dessa forma, contextualizar o ensino desse componente curricular ou desenvolver os conceitos matemáticos através da resolução de problemas podem oferecer informações ou subsídios para que os estudantes resolvam problemas da sua "vida real", e ainda, contribuir para o aumento das possibilidades de "matematização" desses sujeitos (FERREIRA; BURIASCO, 2015, p. 454).

Ao se pensar na metodologia de ensino da Etnomatemática e da Resolução de Problemas, pode-se perceber um elo entre ambas as perspectivas, ou seja, reconhecer a realidade do aluno e valorizar seu contexto de vida, procurando explorar e valorizar: elementos, 
conceitos e características matemáticas presentes nos meios em que estão inseridos, intencionando auxiliá-los no processo de aprendizagem da Matemática.

Nessa direção, Pereira (2017, p. 35) comenta que "a Resolução de Problemas e a Etnomatemática andam juntas, pois ambas requerem o conhecimento prévio e prezam pelo saber/fazer do indivíduo". Conhecimentos prévios advindos do processo de interação do aluno com o meio em que está inserido, com habilidades de saber resolver problemas, sendo capaz de fazer tais habilidades nos diversos ambientes em que se insere.

Acreditamos, então, que as práticas de ensino desenvolvidas na modalidade da EJA ou do PROEJA devem explorar elementos da Etnomatemática, tais como: as vivências, as histórias e a cultura dos alunos nos ambientes de ensino, intencionando promover o ensino da Matemática através da Resolução de Problemas, inserindo-se, durante as aulas, situaçõesproblemas que fazem parte das interações dos estudantes com o seu meio, pois compreendemos que, dessa forma, os conceitos matemáticos abordados em sala terão um significado maior para os mesmos quando estiverem fora dos ambientes institucionais de ensino, e ainda se apresentarão mais motivados para aprender os conteúdos curriculares da Matemática, conseguindo, dessa forma, perceber com maior facilidade a importância desses conceitos para a vida.

\section{A PRÁtica NO 4º SEMESTRE do PROEJA}

Conforme antecipado, a proposta didática que ora relatamos foi desenvolvida no IFMT - Campus Pontes e Lacerda, com os alunos da turma do $4^{\circ}$ semestre do PROEJA do Curso Técnico em Comércio, no ano de 2017. Essa turma possuía oito alunos matriculados, sendo três do sexo masculino e cinco do sexo feminino, mas apenas cinco eram frequentes (dois do sexo masculino e três do feminino), nessa época; contou também com a colaboração do professor regente da disciplina de Matemática que, em conjunto com os pesquisadores, elaboraram práticas utilizando o software GeoGebra no ensino do conteúdo de Função do $1^{\circ}$ Grau.

O primeiro passo tomado pelos pesquisadores foi a observação de duas aulas em dois dias diferentes, que se realizava no período noturno. O professor regente ministrava sua aula de forma expositiva e dialogada sobre os conteúdos de Função do $1^{\circ}$ Grau, e os alunos ouviam e participavam. Simultaneamente aos ensinamentos, o docente ia esclarecendo as dúvidas oriundas desse conteúdo, e também buscava a participação dos mesmos no desenvolvimento da aula. Em ambas as aulas, realizaram-se atividades nas quais os alunos buscavam resolvê-las com o auxílio do professor e dos colegas. 
Após essas atividades no caderno, o professor regente, que conhecia o software GeoGebra, planejou, juntamente com os pesquisadores, uma proposta de ensino que possibilitasse aos alunos utilizar esse software no desenvolvimento de gráficos de funções do $1^{\text {o }}$ grau, visto que os mesmos já estavam desenvolvendo gráficos desse conteúdo.

A proposta contemplava, primeiramente, em levá-los para o laboratório de Matemática da instituição, onde havia cinco computadores com o software instalado; na sequência, apresentar o software para a turma e mostrar o desenvolvimento de um gráfico de uma função do $1^{\circ}$ grau utilizando o GeoGebra; por fim, propor aos alunos que realizassem os gráficos de forma similar. A proposta foi apresentada e aceita pelos alunos, os quais se mostraram empolgados com a mesma.

No laboratório de Matemática, os alunos rapidamente compreenderam como era o processo de construção do gráfico, e logo começaram a desenvolver a seguinte atividade: encontrar três coordenadas quaisquer de uma função do $1^{\circ} \mathrm{Grau}$; marcar as três coordenadas utilizando a ferramenta ponto; depois, utilizando a ferramenta reta, traçar uma reta que interligasse os pontos, representando, assim, o gráfico da função pré-definida pelo professor.

Eles procuravam, primeiramente, as coordenadas da função no caderno e depois construíam os gráficos utilizando o GeoGebra, como mostrado na Figura 1. Essa prática de elaborar gráficos no GeoGebra foi realizada em dois dias diferentes, com duas aulas de 50 minutos cada.

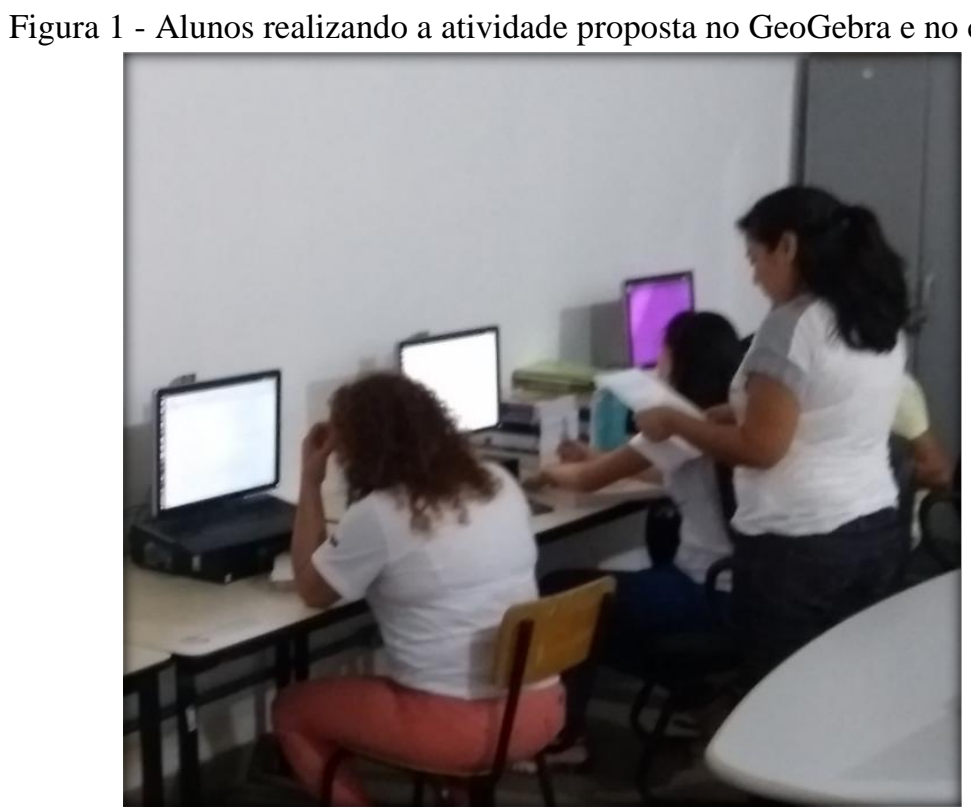

Fonte: Os autores, 2017. 
Durante o acompanhamento dessas aulas, e por meio da observação dos diálogos estabelecidos entre pesquisadores, alunos e professor regente, foi identificado que na turma havia: uma costureira, um pedreiro, um servente e duas donas de casa. E como o próximo passo definido pelo professor regente seria apresentar problemas sobre o conteúdo de Função do $1^{\circ}$ Grau, propomos aplicar um questionário contendo quatro problemas envolvendo o conteúdo de funções que destacassem essas experiências dos alunos.

Nessa segunda prática, planejamos solicitar aos alunos que eles utilizassem o GeoGebra para elaborar desenhos referentes às suas vivências, ao seu cotidiano. E na sequência, com base nesses desenhos, formularíamos problemas envolvendo o conteúdo de Função do $1^{\circ}$ Grau ou elaboraríamos uma nova prática envolvendo a generalização de funções do $1^{\circ}$ grau partindo desses desenhos.

Contudo, para não comprometer as aulas do professor regente, pois acreditávamos que para a realização dessa segunda prática seriam necessárias aproximadamente quatro ou seis aulas, criamos apenas, com o auxílio do GeoGebra, situações-problemas que permeavam as profissões desses sujeitos, inerentes às atividades diárias, ou ainda, que os problemas elaborados abrangessem de alguma forma o Curso Técnico em Comércio.

Dessa forma, apresentamos problemas envolvendo: a compra de um brinquedo, pois todos eram casados e tinham filhos; o pagamento de uma conta; a realização da pintura de uma casa; e a produção de roupas. Como mostram as Figuras 1, 2, 3 e 4.

Figura 2 - Problemas apresentados na questão 1

1) Em uma loja de brinquedos há uma variedade de carrinhos à venda, como mostra a figura a seguir:

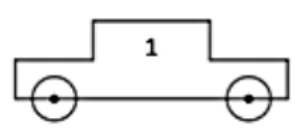

R\$ 5,00

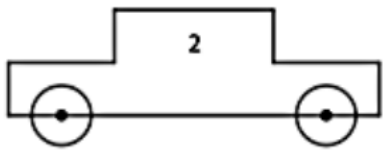

RS 7,00

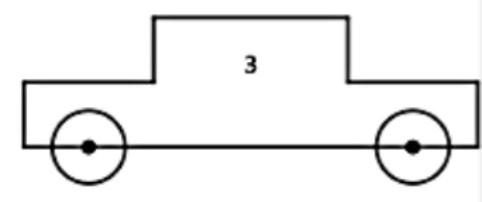

RS 9,00

a) Sabendo que nessa loja possui outros tipos de carrinhos com valores nesse mesmo padrão, qual o valor do carrinho número 4 e 5 ?

b) Represente essa situação por meio de uma função.

Fonte: Os autores, 2017. 
Figura 3 - Problemas apresentados na questão 2

2) Em uma fábrica de roupas onde se confecciona bermudas dos tamanhos PP, P, M, G, GG e XG, verificou-se que a medida da cintura das bermudas são respectivamente:

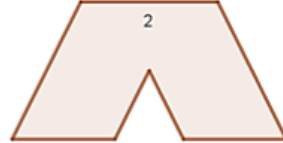

PP

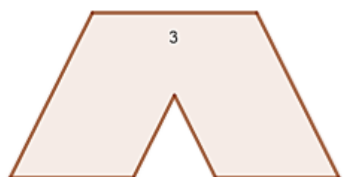

$\mathbf{P}$

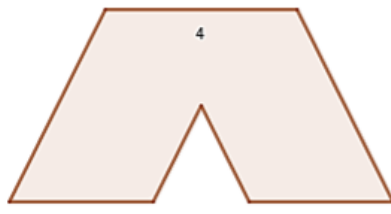

m

a) Qual será a medida da cintura da bermuda G, GG e XG?

b) Como podemos representar essa situação por meio de uma função?

Fonte: Os autores, 2017.

Figura 4 - Problemas apresentados na questão 3

3) Seu José foi comprar tintas no material de construção, Só Tintas, para pintar sua casa. Percebeu que a lata de 1 litro de tinta, custava RS 12,00, a lata de 2 litros custava $R \$ 14,50$, a de 3 litros $R \$ 17,00$ e assim sucessivamente:

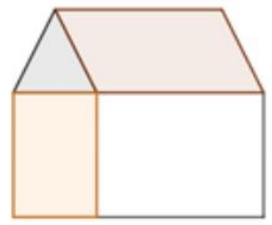

a) Qual seria preço da tinta de 4 litros?

b) Qual é a função que pode representar o valor da tinta?

c) Se uma tinta custa RS 24,50 , qual é a quantidade de tinta dessa lata?

Fonte: Os autores, 2017.

Figura 5 - Problemas apresentados na questão 4

4) A taxa cobra por atraso no pagamento de um boleto é de $\mathrm{R} \$ 2,10$ o dia de atraso. Sabendo que o boleto de Roberta é de R $\$ 35,00$, complete a tabela ao lado e responda:

a) Onde podemos encontrar uma função?

b) Qual é finalidade de se estudar a função do $1^{\circ}$ grau?

c) Que tipo de função foi abordado nos exemplos acima?

\begin{tabular}{|c|c|}
\hline Dias de Atraso & Valor a Pagar \\
\hline 0 & 35,00 \\
\hline 1 & $35,00+2,10$ \\
\hline 2 & \\
\hline 3 & \\
\hline 8 & \\
\hline 19 & \\
\hline$x$ & \\
\hline
\end{tabular}

Fonte: Os autores, 2017.

Nesses problemas, buscamos explorar algumas habilidades matemáticas referente aos conceitos algébricos intrínsecos no estudo de funções: reconhecer a partir da aritmética que um número pode ser representado por uma letra (Questões 1, 2, 3 e 4), calcular as imagens das 
funções (Questões 1, 2, 3 e 4), generalizar as situações-problema em uma Função do $1^{\circ}$ Grau, calcular as imagens das funções generalizadas (Questões 3 e 4) e favorecer a percepções dos alunos para as possíveis criações de modelos matemáticos que podem ser gerados a partir de estudos de situações reais do contexto humano.

Com base nessas duas práticas buscaremos discutir no capítulo seguinte a importância da Resolução de Problemas e da Etnomatemática, por meio dessas atividades com tecnologias digitais nessa turma do PROEJA.

\section{ReSultados E Discussões}

A primeira prática realizada com os alunos se consistiu em elaborar gráficos de função do $1^{\circ}$ grau com o software GeoGebra. Com essa prática foi possível perceber que no primeiro dia, os alunos se mostraram empolgados em realizar as construções das funções no software. Eles perceberam que o software agilizava o processo de construção dos gráficos, reforçaram o importante conceito de que o gráfico característico de uma Função do $1^{\circ}$ Grau gera sempre uma reta, encontram coordenadas através de uma função qualquer e marcaram coordenadas no Plano Cartesiano.

A elaboração de atividades descontextualizada com a vida dos alunos ou com aplicações fora da matemática, realizada nessa primeira prática, explorou nos alunos o que Trefferes define como "matematização", que segundo Ferreira e Buriasco (2015), refere-se

[...] à essência da atividade matemática, à linha que atravessa toda educação matemática voltada para a elaboração de conhecimento factual, à aprendizagem de conceitos, à obtenção de habilidades e ao uso da linguagem e de outras organizações, às habilidades na resolução de problemas que estão, ou não, em um contexto matemático. (FEREIRA; BURIASCO, 2015, p. 454)

As habilidades matemáticas nesse contexto, independe de uma aplicação cotidiana, podendo apresentar, às vezes, aplicações apenas na matemática ou simplesmente não conter nenhuma aplicação.

Por outro lado, o conteúdo de funções abrange várias ciências, por exemplo: a Física, a Geografia e a Economia e seu estudo envolve várias habilidades e capacidades que podem ser exploradas no ensino da Matemática, dentre elas: a leitura e escrita Matemática, a interpretação e construção de gráficos, a compreensão de comportamentos da natureza ou de fenômenos intrínsecos aos contextos humano (NASCIMENTO, 2016).

De acordo com Nascimento (2016, p. 20), o ensino de funções deve "garantir que o aluno adquira certa flexibilidade para lidar com o conceito de funções em situações diversas”. 
Para esse autor, os conceitos, as representações gráficas e as operações matemáticas necessitam ser exploradas. Contudo, essas habilidades precisam permitir o link do mundo escolar com o mundo real dos estudantes, diz o autor:

Os assuntos abordados não podem estar desconexos da realidade do discente, sob o risco de perda de interesse da disciplina e, em cenário mais trágico, a ocorrência de evasão escolar. A matemática deve ser uma ferramenta útil na inferência de conclusões acerca de matemática e na modelagem de problemas. (NASCIMENTO, 2016, p. 20)

Talvez pelo fato de termos apresentado na primeira prática atividades sem as devidas contextualizações inerente a esse conteúdo, a reação dos alunos não tenham sido tão promissora no segundo dia, quanto no primeiro. Sendo possível perceber na Figura 1, uma das alunas com a mão na cabeça, mostrando-se insatisfeita com a realização da proposta.

Refletindo sobre a prática apresenta aos alunos e sobre a postura dessa aluna, percebemos que as tecnologias digitais não devem ser utilizadas sem um contexto, abordando apenas a disciplina de matemática de forma isolada, sem aplicação. Pois como comenta Kenski (2012),

Por mais que as escolas usem computadores e internet em suas aulas, estas continuam
sendo seriadas, finitas no tempo, definidas no espaço restrito de salas de aula, ligadas
a uma única disciplina e graduadas em níveis hierárquicos de aprofundamento dos
conhecimentos em áreas específicas do saber. Professores isolados desenvolvem
disciplinas isoladas, sem maiores articulações com temas e assuntos que têm tudo a
ver o outro, mas que fazem parte dos conteúdos de uma outra disciplina, ministrada
por um outro professor. (KENSKI, 2012, p.45)

Assim, na tentativa de superar o desconforto de alguns alunos e promover atividades que colocassem os alunos de forma ativa no processo de ensino, realizando as atividades de forma participativa, promovendo o envolvimento, a motivação dos alunos pelo conteúdo estudado, propomos a segunda prática. Nesta, buscamos valorizar as experiências desses estudantes, apresentando 4 questões que evidenciavam as suas vivências, que foram identificadas a partir do diálogo com os estudantes do $4^{\circ}$ semestre do PROEJA.

Promover o diálogo, buscando dos alunos os conhecimentos abarcados pelas suas experiências, torna-se no PROEJA ou na EJA, uma responsabilidade pedagógica do docente. Pois como comenta Freire (1981, pag. 96) "o dialogo faz uma relação horizontal, em que a confiança de um pólo no outro é consequiência óbvia". E ainda comenta que, se "o diálogo não provocasse esse clima de confiança entre seus sujeitos", esse processo seria uma contradição.

Mesmo não conseguindo executar o planejamento idealizado inicialmente para essa segunda prática, que consistia em deixar com que os alunos utilizassem o GeoGebra para elaborar desenhos referentes às suas vivências, ao seu cotidiano. E na sequência, com base 
nesses desenhos, formularíamos problemas envolvendo o conteúdo de Função do $1^{\circ}$ Grau. Decidimos inserir as 4 questões destacadas nas Figura 2, 3, 4 e 5, que envolvem as experiência profissionais, as possíveis situações-problemas que se relacionavam com as realidades desses alunos, e preocupamos em abordar a Matemática de forma que essas experiências se aproximasse das especificidades técnicas do curso que eles realizavam.

Isso trouxe um significado maior para os alunos do que quando eles realizavam cálculos ou desenvolviam gráficos sem fazer as devidas relações com as suas histórias e suas vivências. Nesse sentido, comenta Freire (1981, p. 85), "a percepção ingênua ou mágica da realidade" em meio ao processo de ensino, pode corroborar para que os novos conhecimentos sejam perceptíveis. Pois dessa forma, esses conhecimentos estarão entrelaçados com "a realidade que lhes pareciam em si inexorável". Ainda para esse autor, valorizar a realidade dos estudantes pode aprofundar "a tomada de consciência da situação, os homens se "apropriam" dela como realidade histórica, por isso mesmo, capaz de ser transformada por eles" (FREIRE, 1981, p.85).

Dessa forma, ao visualizarem as questões, pode-se perceber que alguns alunos se mostraram surpresos e animados com as atividades, principalmente o pedreiro e a costureira, pois viram que as atividades propostas tinham relação com o trabalho deles. Todos ficaram entusiasmados com as questões e não queriam sair da sala sem terminar de resolver os problemas.

Com a aplicação da questão número 4 , buscamos perceber se os alunos conseguiam relacionar o conteúdo de funções às suas vivências fora de sala de aula, e assim responderam: podemos encontrar uma função "em várias situações do cotidiano, na realização de uma compra, no pagamento de uma conta". Quase todos remeteram aos próprios exemplos apresentados nos questionários. Porém, o pedreiro, durante a realização dos exercícios, comentou que: "agora eu estou começando a entender para que servem essas letras".

Outros dois resultados importantes da prática, e que merecem ser aqui mencionados, foram relatados pelo professor regente após o enceramento das atividades. O primeiro se refere a uma das alunas que tinha faltado no dia da segunda proposta de ensino, mas que na aula seguinte, chegando em sala, queria resolver as questões que envolviam as vivências da turma. E o segundo, uma aluna, que já tinha desistido do curso, retornou para as aulas, e segundo o professor, "ela chegou perguntado sobre a aula no computador que havia perdido, e também sobre as atividades que ela não tinha feito”. Referia-se, portanto, às duas práticas desenvolvidas anteriormente, as quais tinham sido comentadas no grupo de WhatsApp dos alunos dessa turma. 
Nesse sentido, percebemos que se faz necessário que o docente que atua nessa modalidade (EJA) proponha o diálogo, oportunize as trocas de conhecimentos durante o processo de ensino, e que realize atividades de sala de aula que ressaltem as vivências, os saberes já adquiridos por esses educandos fora das salas de aula, e ainda, que explore as tecnologias digitais no ensino da Matemática, pois os jovens e adultos, assim como as crianças e adolescentes do século XXI (KENSKI, 2014), também esperam práticas de ensino dessa natureza.

No que se refere ao diálogo e as vivências dos alunos, Freire comenta que na educação de adultos, não se pode deixar de fazer referência aos aspectos referente as experiências desses sujeitos, às suas práticas. Em sua concepção, a educação de adultos, demanda uma "relação de autêntico diálogo" (FREIRE, 1981, p. 40). Em que ambos os sujeitos, possuem o papel de criar, refletir criticamente e construir significados pelo objeto a ser conhecido.

Em consonância com esse pensamento D’Ambrósio (2008, p. 11) comenta que, dar a palavra ao estudante é "propor situações gerais, não apenas ensinar como resolver e explicar uma situação artificialmente criada pelo professor", mas possibilitar que alunos possam trazer elementos de suas vivências para o espaço de ensino, deixando, por exemplo, os problemas encontrados em livros didáticos que pouco representam a realidade dos alunos; mas por outro lado, ouvir, extrair e desenvolver práticas de ensino com base nesse processo dialético.

Como anteriormente comentado, muitos professores apontam que os alunos da EJA apresentam várias carências ou dificuldades conceituais, as quais podem ter sido ocasionadas pela ruptura no processo de escolarização. A turma do $4^{\circ}$ semestre do PROEJA não se diferenciou dessa realidade, porém o processo de resolução de problemas através da vivência desses alunos possibilitou que os mesmos se arriscassem mais, superassem suas limitações quanto aos conhecimentos prévios da Matemática, buscando resolver as questões elaboradas, pois esses problemas poderiam surgir na vida desses estudantes, de alguma forma. Assim, o professor pôde exigir mais dos alunos e foi possível abordar generalização de funções, ou seja, um conteúdo que não é imediato em Matemática, mas é importante no ensino de funções.

Utilizar o software GeoGebra no desenvolvimento de gráficos de Funções do $1^{\circ}$ Grau também foi uma proposta que chamou a atenção dos alunos nessa prática. Contudo, acreditamos que deixar os alunos construírem as figuras relacionadas às suas experiências no GeoGebra, e posteriormente a essa etapa, o professor desenvolver problemas baseados nessas, trabalhando a modelagem de funções do $1^{\circ}$ grau e, por último, realizar a construção de gráficos no software, 
pode ser uma alternativa mais coerente para essa prática, podendo potencializar os processos de ensino e de aprendizagem.

Salientamos que a utilização das tecnologias digitais é uma necessidade para a educação atual, inclusive para os jovens e adultos (SHIROMA; LIMA FILHO, 2011). Porém, a utilização dessas tecnologias, do computador, precisa ser usada de "forma pedagogicamente correta, é preciso respeitar as especificidades do ensino e da própria tecnologia para garantir que o seu uso, realmente, faça diferença" (KENSKI, 2012, p.46).

Compreendemos, então, que todo o processo de ensino, desde o que foi iniciado pelo professor regente até o que elaboramos e executamos em conjunto, teve influências positivas no processo de aprendizagem dos alunos. Contudo, acreditamos que, o ato de criar e apresentar problemas matemáticos para os alunos do PROEJA sobre o conteúdo de Função do $1^{\circ}$ Grau, envolvendo as vivências, as experiências profissionais, e supondo possíveis situaçõesproblemas que poderiam surgir em suas realidades, baseando-nos no diálogo, propiciou um ambiente de ensino mais profícuo do que quando esses elementos da Etnomatemática e da Resolução de Problemas ainda não eram explorados.

Trabalhando dessa forma, percebemos também que a turma desejava adquirir os conhecimentos matemáticos apresentados na aula. $\mathrm{O}$ ensino da matemática se tornou mais atraente, com significado para os alunos e mais dinâmico, com a participação dos alunos no processo de ensino e com o envolvimento ativo deles, na busca pelos conhecimentos abordados nas aulas.

\section{CONSIDERAÇÕES FINAIS}

Inicialmente, este trabalho apresentou algumas dificuldades encontradas na modalidade de Educação de Jovens e Adultos, e na intenção de contribuir com os processos de ensino e de aprendizagem em Matemática, especificamente no conteúdo Funções do $1^{\circ}$ Grau, buscamos, em duas metodologias de ensino, a Etnomatemática e a Resolução de Problemas, tentar minimizar tais dificuldades.

Mostramos, então, que quando se inserem elementos dessas duas metodologias nas práticas de ensino, a Matemática não é vista apenas como uma disciplina estudada em uma instituição de ensino, que não possui qualquer relação com a vivência do aluno. Pelo contrário, esse componente curricular, abordado sob essas perspectivas, pode preparar o aluno dessa modalidade para viver em sociedade, saber resolver problemas nos ambientes em que se insere, 
e também contribuir para sua permanência nessa modalidade, que possui um alto índice de evasão.

Além disso, revelou que, a partir da prática com os alunos do $4^{\circ}$ semestre do PROEJA, os jovens e adultos da "era digital" esperam utilizar tecnologias digitais no processo de ensino. Dessa forma, cabe ao docente oportunizar a participação ativa dos mesmos durante esse processo: ouvindo, dialogando, extraindo conceitos matemáticos dessas experiências e contextualizando tais vivências nas atividades e tarefas propostas.

Por fim, esperamos que este trabalho possa fomentar a realização de práticas de ensino que favoreçam a dinâmica nos ambientes educacionais, explorando o uso das tecnologias digitais, o diálogo e valorizando as vivências dos estudantes da modalidade da EJA. Ademais, que possa contribuir com o desenvolvimento de propostas de ensino da Matemática, nas quais a Resolução de Problemas e Etnomatemática estejam presentes nessas práticas, e que sejam capazes de relacionar os conhecimentos escolares com o contexto de vida desses sujeitos.

\section{REFERÊNCIAS}

BORBA, Marcelo de Carvalho; SILVA, Ricardo Scucuglia R. da; GADANIDIS, George. Fases das Tecnologias Digitais em Educação Matemática - Sala de Aula e Internet em Movimento. Autêntica. $1^{\circ}$ ed. Belo Horizonte, 2016.

BRASIL. Ministério da Educação. Documento Base - Programa de Integração da Educação Profissional técnica de nível médio ao Ensino Médio na Modalidade de Educação de Jovens e Adultos - PROEJA. SETEC. Brasília, 2007.

COSTA FILHO, José Vinicius da; COSTA, José Vinicius da; COSTA, Lyssa Gonçalves. A prática docente dos cursos PROEJA no IFMT - Campus Cuiabá: uma perspectiva dos burocratas de nível de rua. Revista Prática Docente (RPD), Confresa, v. 2, n. 1, p. 82- 96, 2017. Disponível em: 〈http://dx.doi.org/10.23926/rpd.v2i1.45〉. Acesso em: 05 fev. 2019.

D’AMBRÓSIO, Ubiratan. O Programa Etnomatemática: uma síntese. Revista Acta Scientiae, São Paulo, v.10, n.1, p. 7 - 21, 2008. Disponível em:

<http://www.periodicos.ulbra.br/index.php/acta/article/view/74 > Acesso em: 02 mar. 2019.

FERREIRA, Nilton Cezar; PEREIRA, Júlio Cézar Santos; LEMOS, Glen Cézar. Heurísticas de Resolução de Problemas: Aspectos do Ensino Sobre Resoluções de Problemas de Matemática. COINSPIRAÇÃO, Barra do Bugres, v.1, n1, 2018. Disponível em: $<$ http://sbemmatogrosso.com.br/publicacoes/index.php/coinspiracao/article/view/15> Acesso em: 02 mar. 2019.

FERREIRA, Pamela Emanueli Alves; BURIASCO, Regina Luzia Corio. Enunciados de Tarefas de Matemática Baseados na Perspectiva da Educação Matemática Realística.

BOLEMA, São Paulo, v. 28, n. 52, 2015. Disponível em: <http://www.periodicos.rc.biblioteca.unesp.br/index.php/bolema/article/view/8875> Acesso em: 05 fev. 2019. 
FREIRE, Paulo. Ação Cultural Para a Liberdade E Outros Escritos. Paz e Terra. $5^{\circ}$ ed. Rio de Janeiro, 1981.

FREIRE, Paulo. Pedagogia do Oprimido. Paz e Terra. $9^{\circ}$ ed. Rio de Janeiro, 1981.

GONÇALVES, Paulo Gonçalo Farias; BANDEIRA Francisco de Assis. A Resolução de Problemas Como método de Ensino: Uma Proposta a Luz da Etnomatemática. VI Congresso Internacional de Educação Matemática. Ulbra, Canoas, Rio Grande do Sul, 2013. Disponível em: 〈http://www.conferencias.ulbra.br/index.php/ciem/vi/paper/viewFile/643/39> Acesso em: 02 mar. 2019.

KENSKI, Vani Moreira. Educação e Tecnologias: o novo ritmo da informação. Papirus. $8^{\circ}$ ed. São Paulo. Campinas, 2014.

LOPES JÚNIOR, Geraldo. Geometria Dinâmica com o GeoGebra no Ensino de Algumas Funções. Dissertação de Mestrado. Universidade Federal de Viçosa. Viçosa, 2013.

Disponível em:

<http://www.locus.ufv.br/bitstream/handle/123456789/5877/texto\%20completo.pdf?sequence =1\&isAllowed =y> Acesso em: 02 mar. 2019.

MARCONDES, Nilsen Aparecida Vieira; BRISOLA, Elisa Maria Andrade. Análise por Triangulação de Métodos: Um Referencial Para Pesquisas Qualitativas. UNIVAP. São José dos Campos, v. 20, n, 35, 2014.

MOLL, Jaqueline (org.). Educação de Jovens e Adultos. Mediação. Porto Alegre, 2004.

MOREIRA, Priscila Rezende. Evasão Escolar Nos Cursos Técnicos do PROEJA Na Rede Federal de Educação Profissional e Tecnológica de Minas Gerais. Dissertação de Mestrado. Universidade Federal de Minas Gerais. Belo Horizonte, 2012.

NASCIMENTO, Igor Alvarenga da Silva. Funções Exponenciais no Ensino Médio: teoria e aplicações. Dissertação de Mestrado. Universidade Federal do Rio de Janeiro - PROFMAT. Rio de Janeiro, 2016. Disponível em:

<http://www.repositoriobc.unirio.br:8080/xmlui/bitstream/handle/unirio/11250/MMat\%20052 016.pdf? sequence $=1 \&$ is Allowed $=\mathrm{y}>$ Acesso em: 02 mar. 2019.

PEREIRA, Maria Izabel da Costa. Diálogos entre a Etnomatemática e Resolução de Problemas na EJA. Dissertação de Mestrado. Universidade Federal do Rio Grande do Norte. Natal, 2017.

ROSA, Milton; OREY, Daniel C., A Modelagem Como Um Ambiente de Aprendizagem Para a Conversão do Conhecimento Matemático. BOLEMA. São Paulo, v.26, n.42A, 2012. Disponível em:

〈http://www.periodicos.rc.biblioteca.unesp.br/index.php/bolema/article/view/5805/4428> Acesso em: 02 mar. 2019.

ROSA, Milton; OREY, Daniel C., Abordagens Atuais do Programa Etnomatemática: delineando um caminho para a ação pedagógica. BOLEMA. São Paulo, v.19, n.26, 2006. Disponível em: 
$<$ http://www.periodicos.rc.biblioteca.unesp.br/index.php/bolema/article/view/1851> Acesso em: 02 mar. 2019.

SHIROMA, Eneida Oto; LIMA FILHO, Domingos Leite. Trabalho docente na educação profissional e tecnológica e no PROEJA. Educação \& Sociedade, v. 32, n. 116, p. 725-743, 2011. Disponível em: < https://www.redalyc.org/pdf/873/87320975007.pdf>. Acesso em: 20 abr. 2019.

TUZZO, Simone Antoniaci; BRAGA, Claudomilson Fernandes. O Processo de Triangulação da Pesquisa Qualitativa: Metafenômeno como Gênese. Revista Pesquisa Qualitativa. São Paulo, v.4, n.5, 2016.

Recebido em:12 de março de 2019.

Aprovado em: 14 de maio de 2019. 